Editorial

\title{
Acknowlegement to Reviewers of Journal of Energy and Power Technology in 2020
}

Journal of Energy and Power Technology Editorial Office

LIDSEN Publishing Inc., 2000 Auburn Drive, One Chagrin Highlands, Suite 200, Beachwood, OH, USA; E-Mail: jept@lidsen.com

Journal of Energy and Power Technology

2021, volume 3, issue 1

doi:10.21926/jept.2101002
Received: January 04, 2021

Accepted: January 04, 2021

Published: January 07, 2021

\begin{abstract}
The editors of Journal of Energy and Power Technology would like to express their sincere gratitude to the following reviewers for assessing manuscripts in 2020. We greatly appreciate the contribution of expert reviewers, which is crucial to the journal's editorial process. We aim to recognize reviewer contributions through several mechanisms, of which the annual publication of reviewer names is one. Reviewers receive a voucher entitling them to a discount on their next LIDSEN publication and can download a certificate of recognition directly from our submission system. Additionally, reviewers can sign up to the service Publons (https://publons.com) to receive recognition. Of course, in these initiatives we are careful not to compromise reviewer confidentiality. Many reviewers see their work as a voluntary and often unseen part of their role as researchers. We are grateful to the time reviewers donate to our journals and the contribution they make.
\end{abstract}

The editors of Journal of Energy and Power Technology would like to express their sincere gratitude to the following reviewers for assessing manuscripts in 2020.

We greatly appreciate the contribution of expert reviewers, which is crucial to the journal's editorial process. We aim to recognize reviewer contributions through several mechanisms, of which the annual publication of reviewer names is one. Reviewers receive a voucher entitling them to a discount on their next LIDSEN publication and can download a certificate of recognition

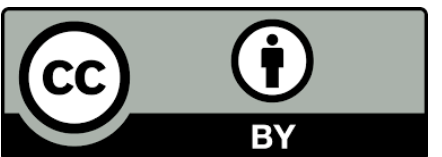

(C) 2021 by the author. This is an open access article distributed under the conditions of the Creative Commons by Attribution License, which permits unrestricted use, distribution, and reproduction in any medium or format, provided the original work is correctly cited. 
directly from our submission system. Additionally, reviewers can sign up to the service Publons (https://publons.com) to receive recognition. Of course, in these initiatives we are careful not to compromise reviewer confidentiality. Many reviewers see their work as a voluntary and often unseen part of their role as researchers. We are grateful to the time reviewers donate to our journals and the contribution they make.

If you are interested in becoming a reviewer for Journal of Energy and Power Technology, see the link at the bottom of the webpage http://lidsen.com/joinus.

The following reviewed for Journal of Energy and Power Technology in 2020:

\begin{tabular}{|l|l|l|}
\hline Silvio Simani & Fabiola Pantò & D Apostolou \\
\hline Jesús González-Cobos & Ceran Bartosz & Alfredo Rocha \\
\hline Tomasz Bednarek & Malek Alkasrawi & Meysam Majidi Nezhad \\
\hline Mohand A. Djeziri & Osamah Siddiqui & Breiffni Fitzgerald \\
\hline Daniel Roger & Huiyao Wang & Radi A. Jishi \\
\hline Axel Löfberg & Muhammad Wakil Shahzad & Shulong Yao \\
\hline Maria Goula & Yassine Amirat & Maria Veronica Sofianos \\
\hline Maria Helena De Sá & Norbert Wagner & Matthew C. Davis \\
\hline Harvey J.M. Hou & Mehdi Mehdi Mortazavi & Hans Hagemann \\
\hline Kakarla Raghava Reddy & Karsten Mueller & A Benato \\
\hline Ssennoga Twaha & Riccardo Basosi & Vishak Balaji \\
\hline Pierpaolo Polverino & Raman Vedarajan & Wenxian Yang \\
\hline Kriston Brooks & Rasin Ahmed & Anastasios P. Vassilopoulos \\
\hline Seyed Niya & William E. Glassley & Monssef Drissi-Habti \\
\hline Stuart M V Gilfillan & I.M. Mujtaba & Justin S. J. Hargreaves \\
\hline Khaled Elsaid & Shi Nee Lou & Hamish A. Miller \\
\hline Adam J. Hawkins & Quentin Meyer & Ciaran Mc Goldrick \\
\hline Michela Martinelli & Kamiel S. Gabriel & Keerti M. Naik \\
\hline Daniel C. Rosenfeld & S. Campagna Zignani & Paul Morgan \\
\hline Marta Victoria & Adrian Pugsley & Junwon Seo \\
\hline Hanan Atia & Andrei Kulikovsky & John L. Haan \\
\hline
\end{tabular}

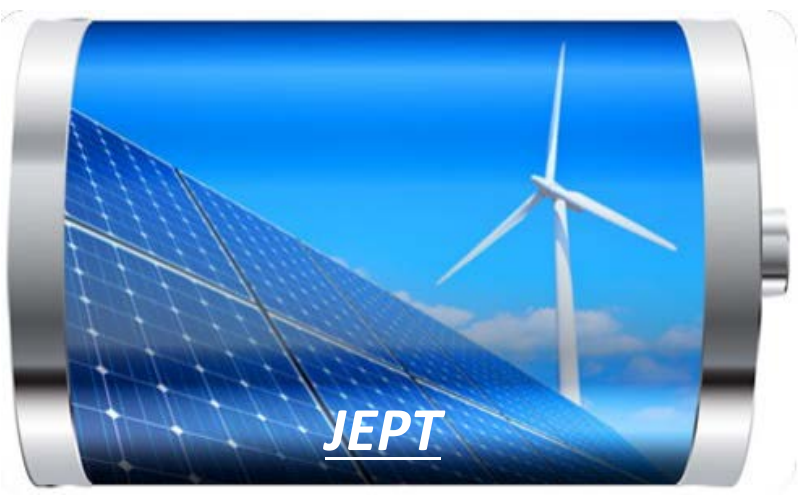

Enjoy JEPT by:

1. Submitting a manuscript

2. Joining in volunteer reviewer bank

3. Joining Editorial Board

4. Guest editing a special issue

For more details, please visit: http://www.lidsen.com/journal/jept 
JEPT 2021; 3(1), doi: 10.21926/jept.2101002 